\author{
Marquette University \\ e-Publications@Marquette
}

College of Nursing Faculty Research and

Publications

Nursing, College of

$4-2013$

\title{
The Effect of Either Topical Menthol or a Placebo on Functioning and Knee Pain Among Patients With Knee OA
}

Robert V. Topp

Marquette University, robert.topp@marquette.edu

Joseph A. Brosky

Bellarmine University

David Pieschel

Bellarmine University

Follow this and additional works at: https://epublications.marquette.edu/nursing_fac

Part of the Nursing Commons

\section{Recommended Citation}

Topp, Robert V.; Brosky, Joseph A.; and Pieschel, David, "The Effect of Either Topical Menthol or a Placebo on Functioning and Knee Pain Among Patients With Knee OA" (2013). College of Nursing Faculty

Research and Publications. 292.

https://epublications.marquette.edu/nursing_fac/292 
Marquette University

e-Publications@Marquette

\title{
Nursing Faculty Research and Publications/College of Nursing
}

This paper is NOT THE PUBLISHED VERSION; but the author's final, peer-reviewed manuscript. The published version may be accessed by following the link in the citation below.

Journal of Geriatric Physical Therapy, Vol. 36, No. 2 (April/June 2013): 92-99. DOI. This article is (C) Section on Geriatrics of the American Physical Therapy Association and permission has been granted for this version to appear in e-Publications@Marquette. Section on Geriatrics of the American Physical Therapy Association does not grant permission for this article to be further copied/distributed or hosted elsewhere without the express permission from Section on Geriatrics of the American Physical Therapy Association.

\section{The Effect of Either Topical Menthol or a Placebo on Functioning and Knee Pain Among Patients with Knee OA}

\author{
Robert Topp \\ College of Nursing, Marquette University, Milwaukee, Wisconsin \\ Joseph A. Brosky \\ Department of Physical Therapy, Bellarmine University, Louisville, Kentucky \\ David Pieschel \\ Department of Physical Therapy, Bellarmine University, Louisville, Kentucky
}

\begin{abstract}
Osteoarthritis $(\mathrm{OA})$ is a common health problem with symptoms including reduced functioning and joint pain. Protracted pharmacological management of knee OA is associated with side effects including gastrointestinal, renal, and neurological dysfunction.
\end{abstract}


Menthol gels have been used with limited empirical support to relieve pain and improve functioning among individual with OA. The purpose of this study was to compare the ability to complete functional tasks and knee pain while completing functional tasks among patients with knee OA after topical application of either $3.5 \%$ menthol gel or an inert placebo gel. Twenty individuals with knee OA volunteered to complete 2 data collection visits 1 week apart. Subjects underwent the same data collection at each visit including the performance of functional tasks and self-reporting knee pain while performing each task. The functional tasks included a 6-Minute Walk (6-MW), the Timed Get Up and Go (TUG), 30-second timed chair stand (TCS), and time to ascend (Up stairs) and descend (Down stairs) a flight of stairs. Subjects reported their knee pain immediately following each functional task using a $100-\mathrm{mm}$ visual analog scale. These assessments of pain and functioning were measured twice at each subject visit: upon arrival at the facility without any intervention and again during the same visit after random application to the OA knee of $5 \mathrm{~mL}$ of $3.5 \%$ menthol gel or $5 \mathrm{~mL}$ of an inert gel.

There were no significant between-group differences or time by treatment interaction in performance of any of the functional tasks, or measures of pain, at any of the data collection time points. However, there were significant within-group differences. Scores on the 6-MW, TCS, and Down stairs functional tasks improved significantly following the application of menthol gel. Scores on the Down stairs functional task improved significantly following application of the placebo gel. The menthol intervention resulted in significant reductions in pain during the TUG, TCS, Up stairs, and Down stairs tasks. The placebo condition did not result in any significant changes in pain during the functional tasks. There were no differences detected in functional tasks or pain following the placebo and menthol conditions. These findings provide partial support regarding the efficacy of menthol gel to improve functioning and reduce pain among knee OA patients.

\section{BACKGROUND}

Osteoarthritis (OA) is the most common form of arthritis and one of the leading causes of pain and disability worldwide. ${ }^{1} \mathrm{OA}$ affects more than 27 million Americans, ${ }^{2}$ with the knee, joint, hip, and wrist the most common sites affected by OA. A recent study estimated that approximately half of all adults will develop symptomatic knee OA by the age of 85 years. ${ }^{3}$ Loss of joint function because of OA is a major cause of work disability and reduces quality of life. The Centers for Disease Control and Prevention estimates that $O A$ and related arthritic conditions cost the US economy nearly $\$ 81$ billion per year in direct medical care. Characteristics of knee OA include a reduced ability to complete functional tasks, decreases in knee strength, decreased knee range of motion, and joint pain. ${ }^{4}$ Knee OA pain is commonly managed pharmacologically with analgesics particularly nonsteroidal anti-inflammatory drugs, in an attempt to preserve the patient's ability to complete functional tasks. Protracted oral pharmacological management of knee OA is associated with significant side effects, resulting in gastrointestinal, renal, and neurological dysfunction. ${ }^{5,}$,

Menthol is used as an active ingredient in many topical ointments and pain-relieving gels such as Biofreeze, Icyhot, and BenGay. ${ }^{7}{ }^{9}$ Menthol is well known for its ability to elicit cold sensations. It also has antinociceptive and counterirritant properties. ${ }^{8},{ }^{10}, 11$ Topically applied gels that contain menthol result in feelings of cold by stimulating the transient receptor potential family of ion channels or (TRPs). TRPs are found throughout the body, but Transient receptor potential cation channel subfamily M member 8 (TRPM8) is found mainly within thermosensitive neurons, which in addition to responding to reductions in temperature also fire in response to menthol. ${ }^{7},{ }^{12}{ }^{16}$ TRPM8 serves as a neuronal sensor of cold temperatures and is essential for innocuous cool and noxious cold sensations. ${ }^{17}{ }^{18}$ Calcium-imaging techniques have demonstrated that application of menthol to cloned TRPM8 cells results in a heavy intracellular influx of calcium ions, causing depolarization due to the opening of nonselective calcium permeable cation channels. ${ }^{7},{ }^{12}{ }^{16}$ This increase in sensitization of the thermosensitive neurons is what leads to the perceptions of coolness with topical menthol application. 
Stimulation of these thermosensitive neurons is also associated with the analgesic effect of topical menthol gels. Afferent thermosensitive neurons that are stimulated by moderate cooling or the application of menthol have been found to have an inhibitory effect on the nociceptive afferent neurons and on the dorsal-horn neurons, which conduct pain impulses to the thalamus. ${ }^{19}$ This analgesic effect of menthol was demonstrated in vitro by Haeseler et al. ${ }^{20}$ when studying the effect of an electrical stimulus applied to human skeletal muscle tissue after the tissue was exposed to menthol. At various application strengths, inactivated sodium channels were measured to determine the effect on depolarization. It was demonstrated that the menthol blocked the alpha subunit of voltage-gated sodium channels, therefore causing hyperpolarization of the nervous membrane and a block in the signal of pain transduction. This study demonstrated that the application of menthol can have an analgesic effect through exerting an inhibitory gate control over nociceptive inputs. There are no studies, to date, which have examined the effect of a topically applied menthol gel on the performance of functional tasks and knee pain among patients with OA. The purpose of this study was to compare the ability to complete functional tasks and knee pain while completing functional tasks among knee OA patients after topical application of either $3.5 \%$ menthol gel or an inert placebo gel. This purpose was addressed by testing the following hypothesis: (H1) The application of 3.5\% menthol to the affected osteoarthritic knee joint will result in improved performance of functional tasks compared to the application of a placebo control. (H2) The application of 3.5\% menthol to the affected osteoarthritic knee joint will result in reduced pain while performing functional tasks compared to the application of a placebo control.

\section{METHODS}

A convenience sample of 20 individuals previously diagnosed with unilateral or bilateral OA of the knee were recruited from the community through notices placed in local newsletters and electronic mailings. A sample size of 20 was considered adequate to detect an effect size of 0.6 in functioning and pain following administration of the menthol and a 0.8-effect size when comparing functioning and pain between the menthol and the placebo. These anticipated effect sizes are consistent with previous authors who have reported the pain-relieving effect of glucosamine sulfate and nonsteroidal anti-inflammatory drugs ${ }^{21}$ and ice therapy ${ }^{22}$ in treating OA. Inclusion criteria were subjects 40 years or older, with a previous diagnosis of knee OA made by a physician, consuming daily scheduled dosages of oral medication to relieve their knee pain, and able to complete a simple battery of functional tasks. Exclusion criteria comprised the exercise-testing exclusion criteria outlined by the ACSM, ${ }^{23}$ inability to travel to the testing site and/or the inability to read and write English at an eighth-grade level. Interested individuals were instructed to contact a member of the research team by phone to complete a brief telephone screen and to schedule an initial appointment to provide written informed consent and to complete data collection procedures. This telephone screening verified the presence of inclusion criteria and the absence of the exclusion criteria. If subjects did not meet any of the exclusion criteria during this telephone screening, they were scheduled for two separate visits to the physical therapy laboratory with each of these visits separated by at least 7 days. During the initial visit, prior to any data collection taking place, subjects provided written consent using a form approved by the university's institutional review board. Subjects then completed a brief demographic questionnaire, which queried age, gender, height, and weight, which was collected at the first of the two visits to the laboratory. The Western Ontario and McMaster Universities Arthritis (WOMAC) index was also collected upon the subject's arrival at the laboratory at both testing sessions prior to any functional tasks being assessed. The WOMAC index is a self-administered tool that yields a score for three dimensions specific to knee OA: pain, stiffness, and physical functioning. Each item on the pain, stiffness, and functional subscales of the WOMAC index requires the subject to respond on a 5-point Likert scale regarding the construct within the last week. Previous authors have established the reliability and validity of this instrument among knee OA patients. ${ }^{24}{ }^{27}$ 
All subjects underwent the same data collection protocol at the same time of day at each of their two laboratory visits. Subjects were instructed to consume their prescribed dose of pain medication at the same prescribed time on both data collection days. Once subjects arrived at the laboratory, they completed five functional tasks in the following order; 6-Minute Walk (6-MW), Timed Get Up and Go (TUG), a number of sit to stand repetitions in 30 seconds (timed chair stands), duration of time required to ascend 13 stairs (Up stairs) and descend 13 stairs (Down stairs). Immediately following completion of each of these tasks, subjects were asked to provide a rating of the pain they experienced during the performance of the task in the knee affected by OA. If both knees were affected, they were asked to report the pain in the more painful of their knees. Following these assessments, one of two randomly selected topical gels was applied to the subject's affected knee and the assessments of performing the functional tasks and pain were again conducted. Subjects were provided with approximately 5 minutes of rest between the initial and second assessment during each visit to the laboratory. A blocking technique was used to randomly assign subjects to receive the menthol or placebo at their initial visit to obtain an even numbers of subjects who received the menthol or placebo at the initial visit. This blocking technique involved each subject selecting one of 20 envelopes inside of which was a card that indicated their initial treatment was either " $\mathrm{A}$ " or " $\mathrm{B}$." The 10 envelopes containing a card with " $\mathrm{A}$ " indicated the subject received the menthol treatment on their initial visit and the placebo at their second visit. The 10 envelopes containing a card with a " $\mathrm{B}$ " indicated the subject initially received the placebo and then received the menthol treatment at their second visit. At 7 days following the initial visit to the laboratory at the same time of day, the alternative gel was applied in the same manner as the first one.

\section{Functional Tasks}

Each subject's ability to complete functional tasks was assessed while they performed 5 standard activities including a 6-MW, sit-to-stand in 30 seconds, TUG, and time required to ascend/descend a flight of 13 stairs). These assessments were performed by the same research staff at the same laboratory over the duration of the study.

The Six minute walk time (6-MWT) is a performance-based test originally developed to assess exercise tolerance in patients with pulmonary disease ${ }^{28}$ with the distance walked in 6 minutes measured and recorded, with a greater distance indicating better functional ability. The 6-MWT has been used previously in other patient populations and as a standard measure of functional mobility in older adults and patients following lower extremity joint arthroplasty. ${ }^{27},{ }^{29}-{ }^{33}$ During each of the two data collection visits to the laboratory immediately following completion of the WOMAC index, the participants completed the 6-MWT. If a participant was currently using an assistive device for ambulation, they were permitted and encouraged to use the device during the test. Each participant was instructed to "walk as fast and as safely as possible, to cover as much ground as possible" for 6 minutes while walking around a 30-meter indoor course marked off in 1-meter increments. Encouragement during this assessment was minimal, and participants were instructed to stop at any point if they experienced pain or fatigue and to resume walking once they were ready. Participants were notified at the end of the third and fifth minute to provide information on time remaining for completing the task. The total distance walked in 6 minutes was recorded to the nearest meter.

The TUG test was originally designed as a functional task used to measure basic mobility, balance, and locomotor performance in older adults with balance disturbances. ${ }^{34}, 35$ The TUG test has been used in many different patient groups including individuals with rheumatoid arthritis, $O A$, and with patients after total knee replacement and has been shown to be reliable and responsive. ${ }^{35}-{ }^{43}$ Following the 6-MWT and a 2 to 3 minute rest period, the participants performed the TUG test as described by Podsiadlo and Richardson. ${ }^{35}$ The TUG test began with the participant in a standard armless chair (45-cm seat height) with both feet flat on the floor. If a participant was currently using an assistive device for ambulation, they were permitted and encouraged to use it for this assessment. The use of an assistive device has been shown to have a significant impact on the 
performance and score on the TUG test. ${ }^{44}$ The TUG test was demonstrated to the participant, and they were instructed to perform the test as "quickly and safely as possible." On the command "go," the participant rose from the chair, walked around a small cone placed 3 meters from the edge of the front of the chair, returned to the chair, and sat down. Participants performed 3 trials, and the fastest time to the nearest 0.1 second was recorded by a stopwatch.

The TCS test involves the number of sit-to-stand repetitions an individual can complete in 30 seconds, with a higher number of repetitions completed indicating a better performance. ${ }^{45}$ Normative age-referenced values for males and females for the 30-second TCS test have been published by Rikli and Jones. ${ }^{45}$ The same standardized armless chair (45-cm seat height) used previously for the TUG test was also used for the TCS test. From a seated starting position, participants were instructed at the word "go" to "stand up completely and sit down safely and as quickly as you can, as many times as you are able in 30 seconds." The score recorded was the number of complete sit-to-standing repetitions performed, disregarding any partially completed repetitions.

Ascending (Up stairs) and descending (Down stairs) have also been reported by previous authors as valid methods of assessing functional ability among patients with knee OA. ${ }^{38}, 40,46$ Evaluation of the performance of ascending and descending stairs has also been shown to be reliable and valid tests of function in patients following total knee replacement. ${ }^{47}$ The relevance of assessing ascending and descending stairs as independent tasks has been suggested as differences in performing these tasks separately may reveal important clinical and functional correlates with other impairments in older adults. ${ }^{48}$ For example, difficulty in ascending stairs has been associated with the presence of hypertension, arthritis, and symptoms of depression, as well as poor balance, and decreased grip strength, whereas difficulty in descending stairs has been associated with a higher frequency of activities of daily living) limitations such as bathing, dressing, and walking inside the house. ${ }^{48}$ Following completion of the TCS test, the participants were instructed to ascend (Up Stairs) and then descend (Down Stairs) a flight of 13 stairs. Handrails were located on both sides of the flight of stairs (rise $=20$ $\mathrm{cm}$ and tread $=27 \mathrm{~cm}$ ). The assessment began with the participant facing the stairs with their hands at their sides standing with both feet on the floor. Participants were instructed and encouraged to use the handrails if needed to maintain balance and safety. At the word "go," the time to ascend, and then descend, was recorded separately to the nearest 0.01 second with a stopwatch. The time started when the participant's foot was lifted initially from the floor and stopped when both feet arrived on the final stair/landing.

Pain was measured immediately following completion of each functional task by asking subjects to rate the pain in their knees on a 100-mm visual analog scale (VAS). The VAS is considered by many to be one of the most clinically useful, valid, and reliable methods of assessing pain intensity ${ }^{49}{ }^{51}$ and has been reported to provide greater sensitivity than a numerical pain scale. ${ }^{51}$ Pain was assessed immediately at completion of each of the functional performance tasks (eg, 6-MWT, TUG, TCS, Up Stairs, and Down Stairs) as indicated by a small vertical mark made by the participant on a 100-mm VAS anchored at one end "no pain" and the other "extreme pain." This resulted in a pain score while performing each of the functional tasks ranging from 0 to 100. The VAS has been demonstrated to correlate well with other measures of pain and exhibit good reliability. ${ }^{53}$

\section{Interventions}

During each laboratory session following initial assessment of the subject's functional ability and pain, one of two randomly selected topical gels was applied to the subject's affected knee. These gels were applied within 5 minutes of completing the initial assessment and immediately prior to the subject beginning their second assessment. The dose of both of these gels was $5 \mathrm{~mL}$, which is consistent with previous studies who reported a treatment effect for menthol containing topical gels ( $1 \mathrm{~mL}$ of gel for every $200 \mathrm{~cm}^{2}$ of surface area). ${ }^{54}{ }^{56}$ The treatment condition selected at the particular laboratory session was applied by a gloved technician to the anterior and posterior knee from the superior patella to the quadriceps insertion over a time period of 
approximately 5 seconds. The experimental treatment condition consisted of 3.5\% menthol (Biofreeze). The placebo treatment consisted of KY jelly, which contains no neuroactive agents, primarily water, glycerin, and gluconolactone.

\section{Analysis}

Descriptive analysis was conducted on all of the variables collected to determine the appropriateness of parametric statistics. Once the assumptions of conducting parametric statistics were verified repeated measures ANOVA with time (preapplication vs postapplication) treatment condition (menthol vs placebo), and interaction (time by treatment) were calculated to address the study hypotheses. These statistics employed the measures of the ability to complete functional tasks and knee pain while completing functional tasks as separate dependent variables. Significant $(P<.05)$ main effects were further explored through Bonferroni post hoc comparisons to determine the specific differences between means within and between the treatment conditions.

\section{RESULTS}

Descriptive statistics of the subject's demographic characteristics (see Table 1) indicated that the sample represented middle-aged, primarily female, overweight patients with knee OA. The subject's performance of the functional tasks was consistent with previous groups of patients with knee OA. ${ }^{26,},{ }^{57}$ Analysis of the subject's responses on the WOMAC index indicated both groups were experiencing a mild degree of pain, stiffness, and functional impairments during the study. These responses on the WOMAC index indicate the sample reported a similar amount of pain, stiffness, and functional disability due to their knee OA as previous samples of independent community-residing knee OA patients who were not contemplating surgical intervention. ${ }^{25},{ }^{26} t$-test comparisons indicated that the subjects did not report statistically different scores on their WOMAC index prior to either of their two data collection sessions in the laboratory (see Table 2).

Table 1: Demographics and WOMAC Scores Prior to Each Laboratory Session

\begin{tabular}{|l|l|}
\hline Characteristic & Mean (SD) \\
\hline Age, $\mathrm{y}$ & $54.94(7.77)$ \\
\hline Weight, kg & $86.05(15.27)$ \\
\hline Height, $\mathrm{m}$ & $1.68(0.12)$ \\
\hline Body mass index & $30.74(5.27)$ \\
\hline Gender & $\mathrm{F}=14(70 \%)$ Mean $=4(30 \%)$ \\
\hline
\end{tabular}

Table 2: WOMAC Scores Prior to Each Data Collection Session

\begin{tabular}{|l|l|l|l|l|}
\hline $\begin{array}{l}\text { WOMAC } \\
\text { Subscale }\end{array}$ & $\begin{array}{l}\text { Laboratory Testing Session 1, Mean } \\
\text { (SD) }\end{array}$ & $\begin{array}{l}\text { Laboratory Testing Session 2, Mean } \\
\text { (SD) }\end{array}$ & $\mathrm{t}$ & $\mathrm{P}$ \\
\hline Pain & $6.50(3.33)$ & $6.25(3.06)$ & 0.58 & .57 \\
\hline Stiffness & $3.65(1.57)$ & $3.15(1.50)$ & 1.69 & .11 \\
\hline Function & $22.70(11.24)$ & $21.00(9.97)$ & 1.19 & .25 \\
\hline
\end{tabular}

Repeated measures ANOVA indicated no significant between-group differences or time by treatment interaction in performance of any of the functional tasks at any of the data collection time points. The analysis also indicated a significant time effect on the performance of 6-MW $(F=11.39, P=.00), \operatorname{TCS}(F=20.99, P=.00)$, and Down stair $(F=6.61, P=.01)$, functional tasks between the pre- and postapplication time points. Post hoc analysis indicated that performance of the 6-MW, TCS, and Down stairs significantly improved as a result of 
applying the 3.5\% menthol gel. This same post hoc analysis indicated that the placebo treatment resulted in improved performance of the Down stairs task only (see Table 3). Significant treatment effect sizes (partial eta square $\left.\eta_{p}^{2}\right)^{58}$ ranged from medium $\left(\eta_{p}{ }^{2}=0.090\right)$ on the Stair up task to large $\left(\eta_{p}{ }^{2}=0.36\right)$ for the TCS task. 
Table 3: Effect of Biofreeze Versus Placebo on the Performance of Activity

\begin{tabular}{|c|c|c|c|c|c|c|}
\hline Activity & Menthol & & & Placebo & & \\
\hline & $\begin{array}{l}\text { Preapplication, Mean } \\
\text { (SD) }\end{array}$ & $\begin{array}{l}\text { Postapplication, Mean } \\
\text { (SD) }\end{array}$ & $\begin{array}{l}\% \\
\text { Change }\end{array}$ & $\begin{array}{l}\text { Preapplication, Mean } \\
\text { (SD) }\end{array}$ & $\begin{array}{l}\text { Postapplication, Mean } \\
\text { (SD) }\end{array}$ & $\begin{array}{l}\% \\
\text { Change }\end{array}$ \\
\hline 6-Min Walk & $459.25(96.11)$ & $472.30(102.67)$ & $2.84^{a}$ & $466.45(87.66)$ & $475.80(86.87)$ & 2.00 \\
\hline TUG & $7.93(1.97)$ & $7.70(2.13)$ & -2.90 & $7.48(2.10)$ & $7.50(1.81)$ & 0.27 \\
\hline $\begin{array}{l}\text { Timed chair } \\
\text { stand }\end{array}$ & $9.58(1.97)$ & $10.29(2.08)$ & $7.418^{a}$ & $9.58(2.12)$ & $10.05(2.11)$ & 4.91 \\
\hline Up stairs & $11.78(6.74)$ & $11.48(7.41)$ & -2.56 & $11.60(6.12)$ & $11.29(6.21)$ & -2.67 \\
\hline Downstairs & $12.01(8.72)$ & $10.97(7.57)$ & $-8.66^{a}$ & $12.52(8.72)$ & $11.21(7.57)$ & $-10.46^{a}$ \\
\hline
\end{tabular}

${ }^{\mathrm{a} A}$ significant within-group change over time. 
The analysis indicated no significant between-group differences or time by treatment interaction in pain while performing any of the functional tasks at any of the data collection time points. The analysis also indicated a significant time effect on the pain reported during the TUG $(F=4.90, P=.03)$, TCS $(F=7.41, P=.01)$, Up stairs $(F=16.60, P=.00)$, and the Down stairs $(F=4.99, P=.03)$ functional tasks. The post hoc analysis found that the menthol condition resulted in significant decline in pain (see Table 4) during the performance of the TUG, TCS, Up stairs, and Down stairs functional tasks. The placebo condition did not result in any changes in pain while performing any functional tasks. The effect sizes on pain while performing these functional tasks as a result of applying the menthol ranged from moderate $\left(n_{p}{ }^{2}=0.12\right)$ for the TUG and the Down stairs task to large $\left(\eta_{p}^{2}=0.30\right)$ for the Up stairs functional task. 
Table 4: Effect of Biofreese Versus Placebo on Pain During Activity

\begin{tabular}{|l|l|l|l|l|l|l|}
\hline Activity & Menthol & & & Placebo & \\
\hline & $\begin{array}{l}\text { Preapplication, Mean } \\
\text { (SD) }\end{array}$ & $\begin{array}{l}\text { Postapplication, Mean } \\
\text { (SD) }\end{array}$ & $\begin{array}{l}\% \\
\text { Change }\end{array}$ & $\begin{array}{l}\text { Preapplication, Mean } \\
\text { (SD) }\end{array}$ & $\begin{array}{l}\text { Postapplication, Mean } \\
\text { (SD) }\end{array}$ & $\begin{array}{l}\% \\
\text { Change }\end{array}$ \\
\hline 6-Min Walk & $24.50(16.91)$ & $21.90(16.68)$ & -10.61 & $29.25(18.82)$ & $25.35(16.83)$ & -13.33 \\
\hline TUG & $26.25(15.06)$ & $19.10(11.33)$ & $-27.24 \mathrm{a}$ & $29.30(16.92)$ & $24.85(16.73)$ & -15.19 \\
\hline Timed chair stand & $36.45(16.72)$ & $22.75(14.07)$ & $-37.59 \mathrm{a}$ & $32.90(18.80)$ & $29.25(18.66)$ \\
\hline Up stairs & $30.75(16.89)$ & $19.60(12.66)$ & $-36.26 \mathrm{a}$ & $34.75(16.13)$ & $28.00(17.58)$ \\
\hline Downstairs & $33.55(19.40)$ & $21.75(15.14)$ & $-35.17 \mathrm{a}$ & $33.20(16.60)$ & $31.15(17.69)$ & -11.09 \\
\hline
\end{tabular}

${ }^{a} A$ significant within-group change over time. 


\section{DISCUSSION}

These findings do not support the study hypotheses that a 3.5\% menthol gel applied to an osteoarthritic knee joint will result in improved performance of functional tasks or pain while performing functional tasks compared to the application of a placebo control. The significant improvements in functioning and pain as a result of the menthol treatment appear to indicate further discussion. The application of $3.5 \%$ menthol to the affected osteoarthritic knee joint resulted in improved performance of 3 of 5 functional tasks, whereas the placebo improved the performance of only 1 of the 5 functional tasks assessed. As well, the application of 3.5\% menthol resulted in significantly less pain while performing 4 of the 5 functional tasks, whereas the placebo condition did not significantly change the subject's pain while performing any of the functional tasks. These promising findings must be tempered by the result that performance of functional tasks and pain was not significantly different following application of the menthol or the placebo conditions. These promising findings may be attributable to a number of factors. By selecting a sample who was functioning at a relatively high level, the effect of the intervention may not of had the potential to substantially improve their functioning or decrease their pain. That is a ceiling effect may have confounded the findings. Another explanation may be that the intervention was not able to produce results beyond the placebo effect of the control condition. Hróbjartsson and Gøtzsche ${ }^{59}$ in their Cochrane Review reported in their study of more than 200 trials that placebo interventions were not found to have important clinical effects in general but may influence patientreported pain, although it was "difficult to distinguish patient-reported effects of placebo from response bias." These authors reported the pooled relative effect for a placebo to be 0.93 (effect of only $7 \%$ ) but significant. The findings of this study seem to be consistent with what these authors would anticipate to be the effect the placebo effect on patient reports of pain (mean change in pain with the placebo $=12.8 \%$ ). The observed difference in pain resulting from the menthol treatment observed in this trial appears clinically meaningful (mean change in pain with the menthol $=33.8 \%$ ) and is perhaps attributable to the menthol intervention.

Although statistically significant the improvement in functioning observed in this study as a result of the menthol intervention may not meet the threshold for clinical significance. Previous authors have established a threshold for clinically significant difference of the 6-MWT to be $25-54$ meters ${ }^{60}$, 61 The statistically significant improvement in the 6-MWT as a result of the menthol did not appear to reach this threshold. Although there is no similar threshold established for TCS and the Down stairs tasks, the clinical importance of $7.42 \%$ and $8.66 \%$ improvements in these tasks, respectively, as a result of the menthol is debatable. Another possible explanation for the significant improvement in the 6-MWT and the TCS test under the menthol condition was that the subjects could easily gauge their performance on these functional tasks (distance walked and repetitions performed) whereas the other functional tasks were timed, and their performance was not disclosed to them by the research staff conducting the assessments. Since the menthol gel has a distinct odor and produces a cooling or "tingling" sensation when applied topically, it was likely that the subjects were aware of which condition contained the menthol content. With this knowledge, subjects may have attempted to increase their performance on the 6-MWT and TCS following application of the menthol treatment. Future researchers conducting similar studies may wish to assess the effect of topical menthol in such a way that the subjects cannot detect the content of the menthol in the gel.

The declines in pain during the functional tasks appear to be clinically significant ranging from $27 \%$ to $37 \%$ decline in pain following the application of the menthol treatment. These observed decreases in pain with the application of the menthol are consistent with the findings of previous investigators who have reported that afferent thermosensitive neurons are stimulated by menthol,,${ }^{12}{ }^{16}$ which in turn inhibit or block the nociceptive afferent neurons, which conduct pain impulses. ${ }^{19}$ This proposed analgesic mechanism of menthol is validated by the results of this study and is consistent with the findings of Gaudioso et al. ${ }^{62}$ who reported that low concentrations of menthol cause analgesia in mice, blocking pain voltage-gated $\mathrm{Na}^{1}$ channels in dorsal root 
ganglion. These authors concluded that menthol is a state-selective blocker of $\mathrm{Na}^{1}$ of nociceptive afferent neurons channels and may have utility as a topical analgesic compound. Thus, the analgesic effects of menthol observed in this study are consistent with the biochemical mechanism of action observed in previous studies and support anecdotal reports that the topical application of menthol produces an analgesic effect.

The results of this study must be interpreted cautiously for a number of reasons. First, neither the researcher nor the subjects were blinded to the treatment conditions or the purposes of the study. This lack of blinding may have resulted in an expectation bias or the Hawthorne effect from both the subject and the researcher collecting the data. Second, the sample was consuming daily dosages of pain-relieving medications, which may have contaminated the findings. The research team considered purposely evoking pain within the sample by asking the subjects not to take their pain medication on the data collection days to be unethical. To minimize the effect of subjects taking their pain medication, they were instructed to take their scheduled pain medications at the same time of day on the days when data were collected and data were collected at the same time of day from each individual subject. This approach maintained the consistency of any effect of the subject's consumption of pain medication on the outcome variables over the data collection points. Furthermore, the results of the WOMAC pain subscale and the functional tasks indicated that the subjects were in mild pain over the previous week with high levels of functional ability similar to previously studied groups of patients with knee OA. These finding may indicate a ceiling effect that any treatment may not be able to reduce the subject's pain or improve their functioning because they were experiencing only mild levels of pain in the previous week and were functioning at a high level. It is interesting to observe that the topical menthol condition resulted in significant reductions in pain in addition to the subject's scheduled pain medications. This additive analgesic effect of topical menthol with the subject's scheduled pain medications supports the validity of the "complimentary" effect of topical menthol to relieve pain. This observation suggests that the analgesic mechanism of action is different between menthol and oral pain medications subjects in this study were consuming and indicates further study in the area. These results provide only the immediate effects of the intervention and clinical applicability to situations where an immediate pain-relieving response is indicated. This immediate analgesic effect may be desirable prior to painevoking treatments including maintaining flexibility or strength of the affected knee joint.

The final limitation of the study was that the repeated-measures nature of the design may have resulted in a familiarization effect with the data collection protocol. Subjects may have performed differently on the functional tasks and had different pain during their second visit to the laboratory based upon becoming familiar with the data collection protocol during their first visit to the laboratory. The impact of this familiarization effect was minimized by randomly assigning the ordering of the menthol and placebo conditions during the first visit to the laboratory and evaluating subjects while they performed familiar functional tasks. The repeated measures design was also selected to minimize wide anticipated differences between knee OA patients on their functional ability and pain previously reported in the literature. ${ }^{63}$ If the small sample in this study were randomized to receive either only a treatment or a control condition, the wide variability in functioning and pain exhibited by knee OA patients may have diluted the statistical power of the findings. Future randomized clinical trials may wish to directly compare the effects of the topical menthol and a placebo control among large randomly assigned groups of knee OA patients to minimize the effect of variability.

The results of this preliminary study may indicate the efficacy of topical menthol to improve the functioning and decrease the pain among knee OA patients. These findings are consistent with previous investigators who have proposed a biochemical mechanism of action for topical menthol as an analgesic. This consistent evidence regarding the effectiveness of topical menthol to relieve pain provides the clinician with another approach to treating pain among knee OA patients. Standard treatment of knee OA pain includes nonsteroidal antiinflammatory drugs, which are accompanied by significant gastrointestinal, renal, and neurological side 
effects. ${ }^{6}$ Using topical menthol to compliment standard pharmacological treatment of knee OA may contribute to enhance pain relief and improve functional ability particularly during pain-evoking activities. Further study is needed to determine how long the pain-impacting effect of the menthol lasts and to provide more insights into the extent to which its effectiveness represents more than a placebo effect.

\section{REFERENCES}

1. Centers for Disease Control and Prevention. Prevalence of self-reported arthritis or chronic joint symptoms among adults-United States 2001. MMWR Morb Mortal Wkly Rep. 2002;51(42):948-950.

2. Helmick CG, Felson DT, Lawrence RC, et al. Estimates of the prevalence of arthritis and other rheumatic conditions in the United States. Part I. Arthritis Rheum. 2008;58(1):15-25.

3. Murphy L, Schwartz TA, Helmick CG, et al. Lifetime risk of symptomatic knee osteoarthritis. Arthritis Rheum. 2008;59(9):1207-1213.

4. Creamer P. Current perspectives on the clinical presentation of joint pain in human OA. Novartis Found Symp. 2004;260:64-74; discussion 74-78, 100-104, 277-279.

5. NSAIDs side effects. Harv Health Lett. 2005;31(2):7.

6. Green GA. Understanding NSAIDs: from aspirin to COX-2. Clin Cornerstone. 2001;3(5):50-59.

7. Macpherson L, Hwang SW, Miyamoto T, Dubin AE, Patapoutian A, Story GM. More than cool: promiscuous relationships of menthol and other sensory compounds. Mol Cell Neurosci. 2006;32(4):335-343.

8. Galeotti N, Di Cesare Mannelli L, Mazzanti G, Bartolini A, Ghelardini C. Menthol: a natural analgesic compound. Neurosci Lett. 2002;322(3):145-148.

9. Yosipovitch G, Szolar C, Hui XY, Maibach H. Effect of topically applied menthol on thermal, pain and itch sensations and biophysical properties of the skin. Arch Dermatol Res. 1996;288(5-6):245-248.

10. Haeseler G, Maue D, Grosskreutz J, et al. Voltage-dependent block of neuronal and skeletal muscle sodium channels by thymol and menthol. Eur J Anaesthesiol. 2002;19(8):571-579.

11. Kraemer WJ, Ratamess NA, Maresh CM, et al. A cetylated fatty acid topical cream with menthol reduces pain and improve functional performance in individuals with arthritis. J Strength Cond Res. 2005;19(2):465-480.

12. Behrendt HJ, Germann T, Gillen C, et al. Characterization of the mouse cold-menthol receptor TRPM8 and vanilloid receptor type-1 VR1 using a fluorometric imaging plate reader (FLIPR) assay. Br J Pharmacol. 2004;141(4):737-745.

13. McKemy DD, Neuhausser WM, Julius D. Identification of a cold receptor reveals a general role for TRP channels in thermosensation. Nature. 2002;416(6876):52-58.

14. Rohacs T, Lopes CM, Michailidis I, Logothetis DE. PI(4,5)P2 regulates the activation and desensitization of TRPM8 channels through the TRP domain. Nat Neurosci. 2005;8(5):626-634.

15. Peier AM, Moqrich A, Hergarden AC, et al. A TRP channel that senses cold stimuli and menthol. Cell. 2002;108(5):705-715.

16. Reid G, Reid G. ThermoTRP channels and cold sensing: what are they really up to? Pflugers Arch. 2005;451(1):250-263.

17. Bautista DM, Siemens J, Glazer JM, et al. The menthol receptor TRPM8 is the principal detector of environmental cold. Nature. 2007;448(7150):204-208.

18. Dhaka A, Murray AN, Mathur J, Earley TJ, Petrus MJ, Patapoutian A. TRPM8 is required for cold sensation in mice. Neuron. 2007;54(3):371-378.

19. Proudfoot CJ, Garry EM, Cottrell DF, et al. Analgesia mediated by the TRPM8 cold receptor in chronic neuropathic pain. Curr Biol. 2006;16(16):1591-1605.

20. Haeseler G, Maue D, Grosskreutz J, et al. Voltage-dependent block of neuronal and skeletal muscle sodium channels by thymol and menthol. Eur J Anaesthesiol. 2002;19(8):571-579. 
21. Selvan T, Rajiah K, Nainar MS, Mathew EM. A clinical study on glucosamine sulfate versus combination of glucosamine sulfate and NSAIDs in mild to moderate knee osteoarthritis. ScientificWorldJournal. 2012;2012:902676.

22. Brosseau L, Yonge KA, Robinson V, et al. Thermotherapy for treatment of osteoarthritis. Cochrane Database Syst Rev. 2003;(4):CD004522.

23. ACSM. Guidelines for Exercise Testing and Prescription. Philadelphia, PA: Lippincott Williams, \& Wilkins; 2010.

24. Jones CA, Voaklander DC, Suarez-Alma ME. Determinants of function after total knee arthroplasty. Phys Ther. 2003;83(8):696-706.

25. Petrella RJ, Bartha C. Home based exercise therapy for older patients with knee osteoarthritis: a randomized clinical trial. J Rheumatol. 2000;27(9):2215-2221.

26. Topp R, Woolley S, Hornyak J, Khuder S, Kahaleh B. The effect of dynamic versus isometric resistance training on pain and functioning among adults with osteoarthritis of the knee. Arch Phys Med Rehabil. 2002;83(9):1187-1195.

27. Topp R, Swank A, Quesada $P$, et al. The effect of prehabilitation exercise on strength and functioning after total knee arthoplasty PM R. 2009;1(8):729-735.

28. Butland RJ, Pang J, Gross ER, Woodcock AA, Geddes DM. Two, Six and Twelve-Minute Walking Tests in respiratory disease. BMJ. 1982;284(6329):1607-1608.

29. Troosters T, Gossenlink R, Decramer M. Six minute walking distance in healthy elderly subjects. Eur Respir J. 1999;14(2):270-274.

30. Boardman DL, Dorey F, Thomas BJ, Lieberman JR. The accuracy of assessing total hip arthroplasty outcomes. $J$ Arthroplasty. 2000;15(2):200-204.

31. Harada ND, Chiu V, Stewart AL. Mobility-related function in older adults: assessment with a 6-minute walk test. Arch Phys Med Rehabil. 1999;80(7):837-841.

32. Lord SR, Menz HB. Physiologic, psychologic, and health predictors of 6-minute walk performance in older people. Arch Phys Med Rehabil. 2002;83(7):907-911.

33. Hurwitz DE, Ryals AR, Block JA, Sharma L, Schnitzer TJ, Andriacchi TP. Knee pain and joint loading in subjects with osteoarthritis of the knee. J Orthop Res. 2000;18(4):572-579.

34. Mathias S, Nayak US, Isaacs B. Balance in elderly patients: the "Get-Up and Go" test. Arch Phys Med Rehabil. 1986;67(6):387-389.

35. Podsiadlo D, Richardson S. The Timed "Up and Go": a test of basic functional mobility for frail elderly persons. J Am Geriatr Soc. 1991;39(2):142-148.

36. Zeni JA, Snyder-Mackler L. Early post-operative measures predict 1 and 2 year outcomes after unilateral total knee arthroplasty: importance of contralateral limb strength. Phys Ther. 2010;90(1):43-54.

37. Freter SH, Fruchter N. Relationship between Timed "Up and Go" and gait time in an elderly orthopaedic population. Clin Rehabil. 2000;14(1):96-101.

38. Mizner RL, Petterson SC, Stevens JE, Axe MJ, Snyder-Mackler L. Preoperative quadriceps strength predicts functional ability one year after total knee arthroplasty. J Rheumatol. 2005;32(8):1533-1539.

39. Maly MR, Costigan PA, Olney SJ. Contribution of psychosocial and mechanical variables to physical performance measures in knee osteoarthritis. Phys Ther. 2005;85(12):1318-1328.

40. Ouellet $\mathrm{D}$, Moffet H. Locomotor deficits before and two months after knee arthroplasty. Arthritis Rheum. 2002;47(5):484-493.

41. Kennedy DM, Stratford PW, Wessel J, et al. Assessing stability and change of four performance measures: a longitudinal study evaluating outcome following total hip and knee arthroplasty. BMC Muskuloskelet Disord. 2005;6:3. 
42. Steffen TM, Hackler TA, Mollinger L. Age and gender-related test performance in community dwelling elderly people: six-minute walk test, berg balance scale, Timed Up and Go Test, and gait speeds. Phys Ther. 2002;82(2):128-137.

43. Yeung TS, Wessel J, Stratford PW, MacDermid JC. The Timed Up and Go Test for use on an inpatient orthopaedic rehabilitation ward. J Orthop Sports Phys Ther. 2008;38(7):410-417.

44. Kristensen MT, Bandholm T, Holm B, Ekdahl C, Kehlet H. Timed Up and Go Test score in patients with hip fracture is related to the type of walking aid. Arch Phys Med Rehabil. 2009;90(10):1760-1765.

45. Rikli R, Jones CJ. Senior Fitness Test Manual. Champaign, IL: Human Kinetics; 2001.

46. Yoshida Y, Mizner RL, Ramsey DK, et al. Examining outcomes from total knee arthroplasty and the relationship between quadriceps strength and knee function over time. Clin Biomech. 2008;23(3):320328.

47. Almeida GJ, Schroeder CA, Gil AB, Fitzgerald GK, Piva SR. Interrater reliability and validity of the stair ascend/descend test in subjects with total knee arthroplasty. Arch Phys Med Rehabil. 2010;91(6):932938.

48. Verghese J, Wang C, Xue X, Holtzer R. Self-reported difficulty in climbing up or down stairs in non-disabled elderly. Arch Phys Med Rehabil. 2008;89(1):100-104.

49. Kahl C, Cleland J. Visual analogue scale, numeric pain rating scale and the McGill Pain Questionnaire: an overview of psychometric properties. Phys Ther Rev. 2005;10(2):123-128.

50. de C Williams AC, Davies HT, Chadury Y. Simple pain rating scales hide complex idiosyncrantic meanings. Pain. 2000;85(3):457-463.

51. Carlsson AM. Assessment of chronic pain. Aspects of the reliability and validity of the visual analogue scale. Pain. 1983;16(1):87-101.

52. Collins SL, Moore RA, McQuay HJ. The visual analogue pain intensity scale: what is moderate pain in millimeters? Pain. 1992;72(1-2):95-97.

53. Boonstra AM, Schiphorst Preuper HR, Reneman MF, Reneman MF, Posthumus JB, Stewart RE. Reliability and validity of the visual analogue scale for disability in patients with chronic musculoskeletal pain. Int $J$ Rehabil Res. 2008;31(2):165-169.

54. Topp R, Winchester L, Mink AM, Kaufman JS, Jacks DE. Comparison of the effects of ice and 3.5\% menthol gel on blood flow and muscle strength of the lower arm. J Sport Rehabil. 2011;20(3):355-366.

55. Topp R, Winchester $L$, Schilero J, Jacks D. Effect of topical menthol on ipsilateral and contralateral superficial blood flow following a bout of maximum voluntary muscle contraction. Int J Sports Phys Ther. 2011;6(2):83-91.

56. Olive JL, Hollis B, Mattson E, Topp R. Vascular conductance is reduced after menthol or cold application. Clin J Sport Med. 2010;20(5):372-376.

57. Swank AM, Kachelman JB, Bibeau W, et al. Prehabilitation before total knee arthroplasty increases strength and function in older adults with severe osteoarthritis. J Strength Cond Res. 2011;25(2):318-325.

58. Cohen JI. A power primer. Psychol Bull. 1992;112(1):155-159.

59. Hrobjartsson A, Gotzsche PC. Placebo interventions for all clinical conditions. Cochrane Database Syst Rev. 2010;(1):CD003974.

60. Mangione KK, Craik RL, McCormick AA, et al. Detectable changes in physical performance measures in elderly African Americans. Phys Ther. 2010;90(6):921-927.

61. Holland AE, Hill CJ, Rasekaba T, Lee A, Naughton MT, McDonald CF. Updating the minimal important difference for six-minute walk distance in patients with chronic obstructive pulmonary disease. Arch Phys Med Rehabil. 2010;91(2):221-225.

62. Gaudioso C, Hao J, Martin-Eauclaire MF, Gabriac M, Delmas P. Menthol pain relief through cumulative inactivation of voltage-gated sodium channels. Pain. 2012;153(2):473-484. 
63. Chan KK, Chan LW. A qualitative study on patients with knee osteoarthritis to evaluate the influence of different pain patterns on patients' quality of life and to find out patients' interpretation and coping strategies for the disease. Rheumatol Rep. 2011;3(1):e3.

\section{Keywords}

Functioning, menthol, osteoarthritis, pain 